\title{
Using Isomorphic Questions, the Statics Concept Inventory, and Surveys to Investigate the Benefits of and Student Satisfaction in a Hybrid Learning En- vironment (Civil Engineering Division)
}

\section{Mr. Eric Kjolsing P.E., University of California, San Diego}

Eric completed his B.S. degree in 2007 and his M.S. degree in 2008 in Structural Engineering from UC San Diego. In 2011, Eric earned his M.B.A. from San Diego State University with a coursework emphasis in finance and a thesis outlining a competitive framework for firms in the transportation industry pursuing Design-Build projects. He is currently pursuing his Ph.D. in Structural Engineering at UC San Diego.

Eric is a licensed P.E. in the state of California and has worked as a bridge engineer for both T.Y. Lin International and Moffatt \& Nichol. Eric has been involved in the design or independent check of a number of projects, most notably: Veterans Memorial Bridge (Portland, ME), Port Mann Bridge (Vancouver, British Columbia), and Milliken Avenue Separation (Ontario, CA).

\section{Dr. Yael Van Den Einde, University of California, San Diego}

Van Den Einde is a Teaching Professor at UCSD. She teaches core undergraduate courses in Structural Engineering, is the chair of the ABET committee responsible for the continuous curricular improvement process, incorporates education innovations into courses (Peer Instruction, Project-based learning), is responsible for TA training (preparing next generation faculty), serves as faculty advisor to student organizations, hears cases of academic misconduct as a member of the Academic Integrity Review Board, and is committed to fostering a supportive environment for diverse students at UCSD by serving on the faculty advisory board for the IDEA Student Center. Her research is focused on engagement strategies for large classrooms and the development of K-16 curriculum in earthquake engineering. 


\title{
Using Isomorphic Questions, the Statics Concept Inventory, and Surveys to Investigate the Benefits of and Student Satisfaction in a Hybrid Learning Environment (Civil Engineering Division)
}

\begin{abstract}
A significant amount of literature is available on the various techniques available for generating an active classroom: publications have advocated the use of group problem solving, peer instruction, in-class demonstrations, body-centered talk, and more. While the benefits of these individual methodologies have been documented, relatively little literature is available on how to best combine these components into a synergistic active learning environment. This is an important issue for foundational classes such as Statics-a course in which physical intuition is developed and utilized over the course of one's career. This paper describes the creation and components of a hybrid learning environment in a Statics course where a variety of pedagogies were implemented. Notable activities included the use of an interactive online textbook, peer instruction, in-class group problem solving sessions, video examples, and instructor led numeric problems. To investigate the effectiveness of the course, and where applicable the individual contributions of unique activities, a number of feedback mechanisms were implemented over the duration of the course. These mechanisms included isomorphic questions to measure the effectiveness of peer instruction, the use of concept inventory exams to measure student learning gains, and a variety of periodically distributed surveys to measure student satisfaction with the individual course components. Findings are presented along with recommendations for how to improve the hybrid course structure.
\end{abstract}

\section{Introduction}

Statics is a fundamental course for civil, structural, mechanical, and aerospace engineering students. Since the course is a prerequisite for a large number of a university's engineering students, it is important to aim for a course structure that both permits the maximization of learning gains and is enjoyable to a majority of students enrolled in the course. Various teaching pedagogies have been investigated over the past two decades with the aim of increasing student learning, student satisfaction, or both: in-class group problem solving ${ }^{[1]}$, peer instruction ${ }^{[2]}$, the use of workbooks ${ }^{[3]}$, physical demonstrations ${ }^{[4]}$, interactive online textbooks ${ }^{[5]}$, body-centered talk $^{[6]}$, inverted or flipped classrooms ${ }^{[7]}$, etc. However, recommendations are scarce on how to best combine these innovative activities into one class: how do we begin to assemble the parts

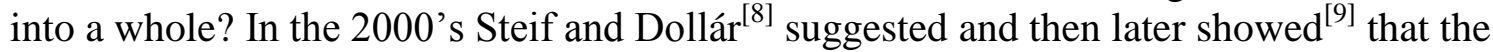
combination of in-class conceptual questions and hands-on physical demonstrations in a Statics class resulted in high learning gains. Researchers later developed ${ }^{[10]}$ and found $^{[11]}$ that supplemental web-based content was also beneficial to student learning. However, while conceptual questions have been shown to increase learning gains in biology ${ }^{[12]}$ and computer science $^{[13]}$, the authors are unaware of similar quantitative finding in a Statics course. Additionally, previous investigations had a strong conceptual emphasis and leaves questions as to how in-class numeric problems, whether instructor led or solved by students within groups, might best be incorporated. 
This paper describes the development and implementation of a hybrid learning environment in a small Statics class. The objectives of the investigation were to: 1) quantify the learning gains stemming from concept questions by incorporating isomorphic questions in a modified peer instruction sequence, 2) determine the effect that activity order had on student responses with regards to two in-class numeric problem solving activities, 3) measure the conceptual learning gains resulting from the described course using a concept inventory exam, and 4) measure and interpret student feedback as to the perceived benefit of the various course components.

\section{The Course}

The semester long course was offered in the fall of 2014 through the Mechanical Engineering department at the University of San Diego. The course instructor was an engineering graduate student with previous experience as a teaching assistant in a traditional Statics course and had undergone training in the use of non-traditional pedagogies. In-class sessions were held in onehour blocks, three times each week.

Since group work would be required, students were instructed to self-form groups. During the first week of the course thirteen groups were formed: twelve groups of three students and one group of four students $(\mathrm{N}=40)$. Due to three students withdrawing from the course the semester concluded with eleven groups of three students and two groups of two students $(\mathrm{N}=37)$. For the duration of the course, students were instructed not to work with other groups during class and at no time were students switched between groups.

\section{Components}

Activities from a traditional classroom, an inverted classroom, and those suggested by Dollár and Steif ${ }^{[8]-[11]}$ were implemented during the semester. Each component of the course is described here.

Interactive Online Textbook $(O T)$. An interactive online textbook was one of two books used in the course. Developed by Dollár et al. ${ }^{[10]}$ and available through the Open Learning Initiative at Carnegie Mellon University, the content focuses on conceptual development and deficiencies arising from traditional teaching methods. This resource differentiates itself from traditional texts by including interactive simulations, assessments, and instant feedback for users. Previous research showed the use of the online textbook resulted in high normalized learning gains ${ }^{[11]}$.

Traditional Textbook (TT) and Online Companion. A traditional bound textbook was the second of two books used in the course. Included with the text was an online course companion containing instructional videos explaining and providing examples of numeric problem solving techniques (VSP). This online companion differed from the interactive online textbook by focusing on numeric problem solving compared to the online textbook's emphasis on conceptual understanding.

Peer Instruction (PI). Developed by Mazur ${ }^{[14]}$ for undergraduate physics courses and successfully used in a variety of other fields ${ }^{[15]}$, the peer instruction sequence calls for 
students to individually respond to a multiple choice conceptual question, discuss the question within peer groups, and then re-respond to the same concept question.

Instructors can use student responses to guide class-wide discussions with the aim of correcting conceptual misunderstandings. Learning gains have been documented in both biolog $\mathrm{y}^{[12]}$ and computer science ${ }^{[13]}$.

Numeric Problems. Full length numeric problems were solved in-class by the instructor (ILPS) in a traditional "white-board" style or by the students during in-class group problem solving sessions (GPS). The numeric problems were developed after the peer instruction concept questions and used to bridge the gap between the conceptual nature of peer instruction and the mathematical skill set instructors hope to generate in traditional classrooms.

Physical Demonstrations (PD). The use of physical demonstrations had been previously advocated in a Statics setting ${ }^{[16]}$ and was implemented in this study to develop a link between the target concept, the required mathematics, and students' physical intuition. An example physical demonstration used in the course is shown in Figure 1. Two students were asked to hold a rope with a known weight positioned at midspan and a force gauge at one end. The tension in the rope was measured at different system angles $(\varphi)$ while a mathematical model describing the systems equilibrium was solved simultaneously.
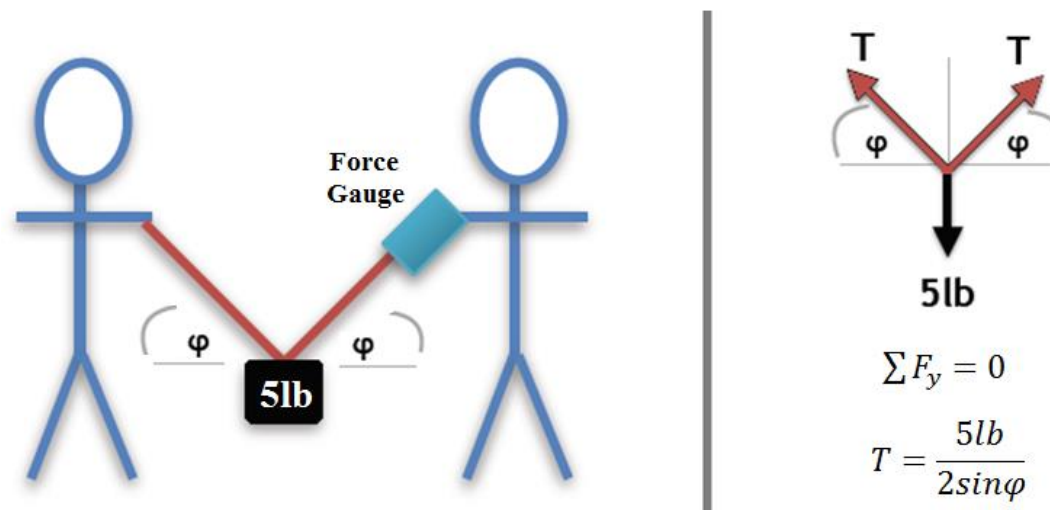

Figure 1. Physical demonstration (left) and mathematical model (right)

Reading Quizzes. To motivate students to read assigned material before class, graded reading quizzes in the form of multiple choice questions were conducted in-class prior to the introduction of each course topic.

In-Class Mini-Lectures. A ten minute mini-lecture was given as each course topic was introduced. This lecture acted to refresh students on their previous reading and allow the instructor to emphasize important aspects of the topic.

Video Lectures (VL). During the second half of the semester the instructor began providing students full length videos of "traditional" lectures prior to the in-class introduction of each course topic. Each video contained a discussion of the upcoming topic and solved numeric problems. Although the combination of in-class mini-lectures 
and the online companion provided similar content, the hour long video lectures were provided to the students as a no-cost additional resource.

Homework and Recommended Problems (HRP). Homework consisted of numeric problems taken from the traditional textbook. Students submitted their solutions electronically through the online companion. Full solutions were made available after each homework submission. Additional numeric problems were recommended, but not collected, prior to each exam.

Exams. Each exam contained numeric problems similar to the recommended problems and multiple choice questions similar in form to the in-class concept questions used during peer instruction. The exams were primarily numeric as conceptual multiple choice questions made up only twenty-percent of all possible points.

Office Hours $(\mathrm{OH})$. Office hours were held immediately before and after class in a group format.

\section{Class Structure}

The course material was divided into seventeen topics (e.g. 2D equilibrium, couples, equivalent loads, etc.) with each topic allotted two one-hour class sessions. Before class, students were expected to have completed assigned readings from either the traditional or interactive online textbook. Additional resources such as video lectures and instructional videos from the online companion were recommended but not required. As each new topic was introduced in-class, students completed a reading quiz, were presented a real-world scenario that highlighted the importance and relevance of the topic, and were then given a mini-lecture to review the pre-class readings. The remainder of in-class time was divided amongst four activities: peer instruction, instructor led problem solving, physical demonstrations, and group problem solving sessions. In general, four peer instruction sequences, up to two instructor led numeric problems, and up to two group numeric problems were used to convey each topic. Physical demonstrations were performed five times during the semester.

A student's overall course grade was based on in-class reading quizzes (10\%), homework (15\%), class participation (5\%), four exams (45\%), and one final (25\%). Due to this method of assessment and exam structure, a majority of the course was numerically based. This is also reflected in the distribution of in-class time where conceptually focused activities accounted for approximately twenty-percent of class time and numeric activities around sixty-percent.

\section{Methods}

\section{Peer Instruction}

To measure the learning gains stemming from peer instruction, the experimental setup used by Smith et al. ${ }^{[12]}$ and Porter et al. ${ }^{[13]}$ was mimicked. Namely, the standard peer instruction sequence (outlined in Components) was modified to include an isomorphic question (see Figure

2). Isomorphic questions are designed to be similar in difficulty and complexity as the paired 
concept question, and investigate student understanding of the same target concept. An example of a paired concept/isomorphic question used in the course is shown in Figure 3.

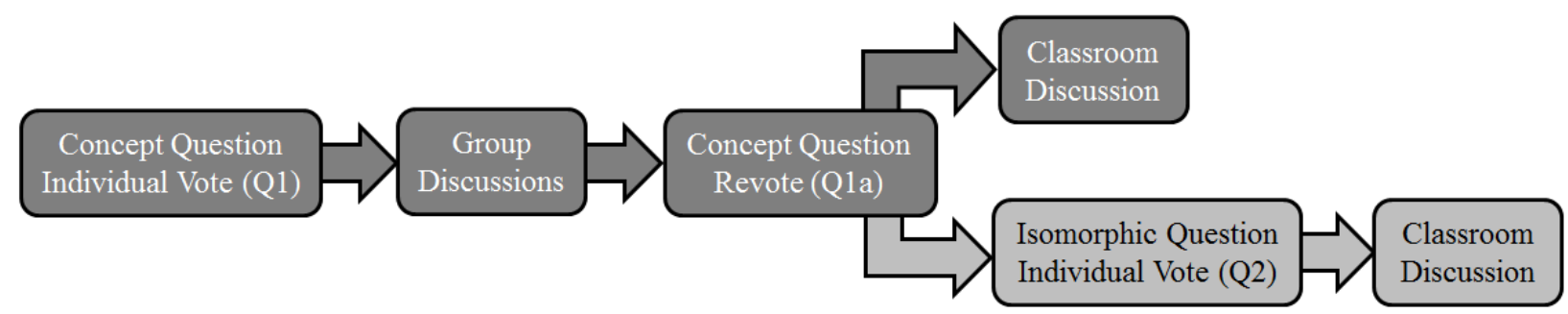

Figure 2. Standard (top track) and modified (bottom track) peer instruction sequence from Porter et al. ${ }^{[13]}$

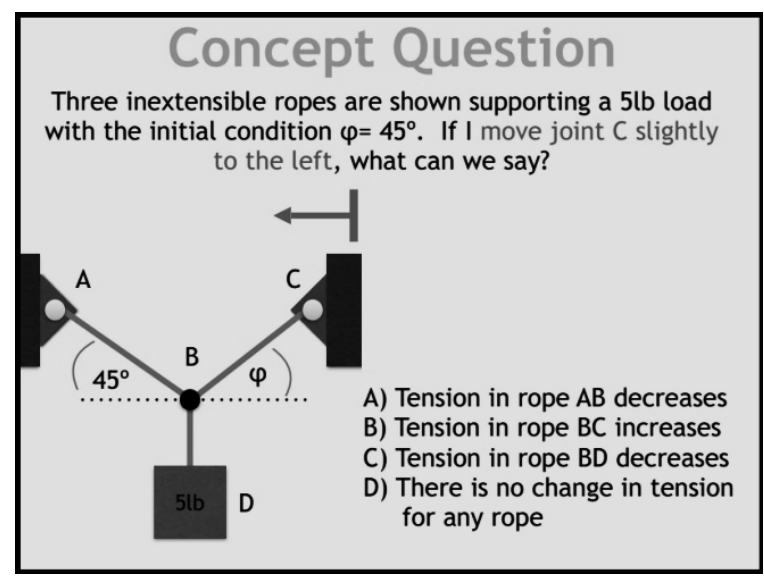

\section{Isomorphic Question}

Three inextensible ropes are shown supporting an $8 \mathrm{lb}$ load with the initial condition $\varphi=35^{\circ}$. If I move joint $C$ slightly to the right, what can we say?

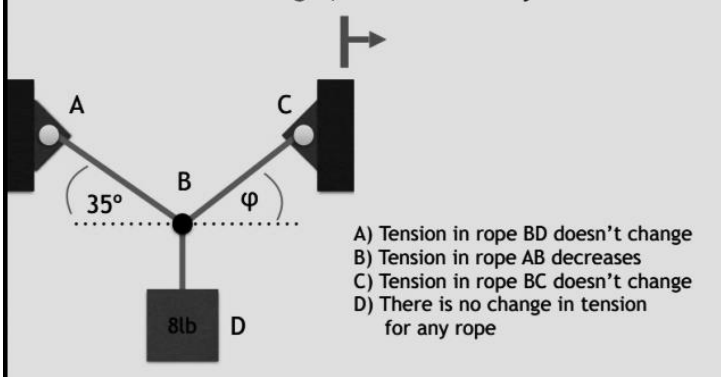

Figure 3. Sample concept/isomorphic question pair

In this modified peer instruction sequence, students respond individually to a posed isomorphic question (Q2) immediately after the concept question revote (Q1a) and before any indication is given by the instructor as to the concept questions (Q1/Q1a) correct answer. The learning gains attributable to peer discussions are then measured by comparing the correct response rate of Q2 and Q1. One may ask why learning gains cannot simply be measured by comparing the correct response rate of Q1a and Q1? As pointed out by James and Willoughby ${ }^{[17]}$, an improved correct response rate from Q1 to Q1a may be due to the correction of a misconception during peer discussions (ideal scenario) or low ability students blindly accepting the answer suggested by their high ability group mates. The knowledge gained during peer discussions can be directly measured by introducing an isomorphic question which targets the same fundamental concept, but requires students to respond without additional instructor or group assistance. In total, fiftyeight concept questions and nine isomorphic questions were posed during the course.

\section{Numeric Problems}

The two types of in-class numeric problem solving activities (instructor led problem solving (ILPS) and group problem solving (GPS)) were presented in one of two sequences. Fourteen times during the course the ILPS occurred during the first session of a topic and the GPS during the second (e.g. on a different day). Six times during the course both problem sets were done in the same session with the ILPS immediately preceding the GPS. The two sequences are shown 
in Table 1. Student responses were recorded during the GPS sessions electronically with the same voting mechanism used during peer instruction.

Table 1. Two numeric problem solving sequences used in the course

\begin{tabular}{|c|c|c|}
\hline $\begin{array}{c}\text { Session/ } \\
\text { Day }\end{array}$ & $\begin{array}{c}\text { Sequence 1 } \\
(\mathbf{n}=\mathbf{1 4})\end{array}$ & $\begin{array}{c}\text { Sequence } 2 \\
(\mathbf{n}=\mathbf{6})\end{array}$ \\
\hline \multirow{2}{*}{1} & ILPS & ILPS \\
\cline { 2 - 3 } & ILPS & GPS \\
\hline \multirow{2}{*}{2} & GPS & ILPS \\
\cline { 2 - 3 } & GPS & GPS \\
\hline
\end{tabular}

\section{Concept Inventory}

Students completed a multiple choice statics concept inventory exam during the first and last week of the course to measure conceptual learning gains stemming from the hybrid environment. The exam tested conceptual understanding in five classes of questions: free-body diagrams, load equivalence, loads at connections, friction forces, and equilibrium conditions ${ }^{[18]}$. Students were given one hour to complete the exams online outside of class.

\section{Survey Distribution}

Three surveys were distributed during the semester asking students which activities they believed were the most beneficial to their understanding of the course material. The first two surveys required students to score both in- and out-of-class activities on their perceived helpfulness using a five-point Likert scale. In the third survey students were asked to rank the various activities; rankings forced students to identify a clear hierarchy as to which activities they found the most helpful. In addition, the third survey asked students to indicate which activities should be continued or discontinued in future courses. The three surveys were distributed at the quarterpoint (during the first exam), the three-quarter-point (during the third exam), and at the end of the course (just before the final).

\section{Results \& Discussions}

In each of the following sections, results are provided for the specified student population. To observe the relationship between students overall course performance and this investigations results, students were classified into two groups: those that had a final course grade above or below the median course grade. Results for these groupings are also provided.

\section{Peer Instruction}

Nine modified peer instruction sequences (MPIS), each containing an isomorphic question, were used during the course to quantify learning gains attributable to peer instruction. Only data from those students who submitted a response to all three questions (Q1, Q1a, and Q2) were included in the following results. 
Student responses were recorded for each peer instruction question as either correct or incorrect and the correct response rate calculated. For example, the percentage of students correctly responding to Q1 was calculated using Equation 1, with other percentages calculated in a similar fashion.

$$
\% \text { of Students with Q1 Correct }=\frac{\sum_{\mathrm{MPIS}=1}^{9}(\# \text { of Students with Q1 Correct })_{\mathrm{MPIS}}}{\sum_{\mathrm{MPIS}=1}^{9}(\# \text { of Student Responses })_{\mathrm{MPIS}}}
$$

The correct response rates were also calculated accounting for question difficulty. Questions were classified as hard, medium, or easy based on the Q1 correct response rate for each modified peer instruction sequence. Quantitatively, the learning gain for a Q2/Q1 pair was calculated using Equation 2 and the normalized gain by Equation 3.

$$
\begin{gathered}
\text { Learning Gain = LG = (\% Correct Q2) }-(\% \text { Correct Q1) } \\
\text { Normalized Learning Gain }=\text { NLG }=\frac{(\% \text { Correct Q2 })-(\% \text { Correct Q1 })}{100 \%-(\% \text { Correct Q1 })}
\end{gathered}
$$

The results of these calculations are shown in Figure 4 and Table 2 where learning gains are apparent across all levels of question difficulty. These results show good agreement with previous investigations ${ }^{[12],[13]}$.

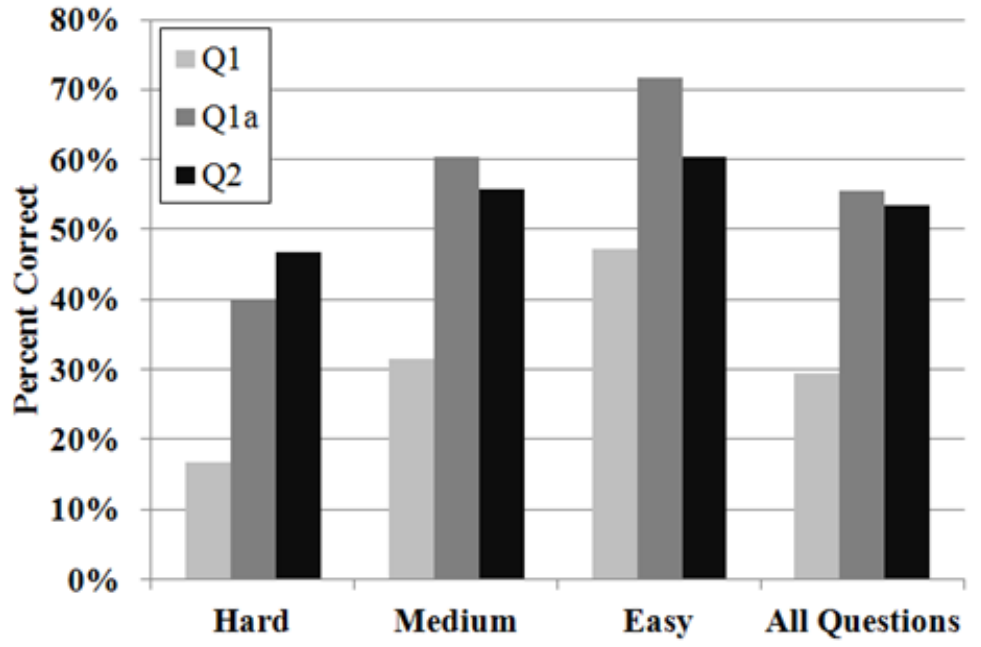

Figure 4. Correct response rates for the modified peer instruction sequences divided by question difficulty

Table 2. Learning gains for the modified peer instruction sequences divided by question difficulty

\begin{tabular}{|c|c|c|}
\cline { 2 - 3 } \multicolumn{1}{c|}{} & LG & NLG \\
\hline Hard & $30 \%$ & $36 \%$ \\
\hline Medium & $24 \%$ & $36 \%$ \\
\hline Easy & $13 \%$ & $25 \%$ \\
\hline All Questions & $24 \%$ & $34 \%$ \\
\hline
\end{tabular}


To evaluate the relationship between course performance and peer instruction based learning gains, the correct response rates of students obtaining an above median (AM) and below median (BM) course grade were calculated. The percentage of AM students answering Q1 correctly was calculated using Equation 4 with other percentages calculated in a similar manner.

$$
\% \text { of AM Students with Q1 Correct }=\frac{\sum_{\mathrm{MPIS}=1}^{9}(\# \text { of AM Students with Q1 Correct })_{\mathrm{MPIS}}}{\sum_{\mathrm{MPIS}=1}^{9}(\# \text { of AM Student Responses })_{\mathrm{MPIS}}}
$$

These results are plotted in Figure 5. It can be seen that students who obtained higher course grades had, on average, higher learning gains then their below median counterparts (see Table 3 ).

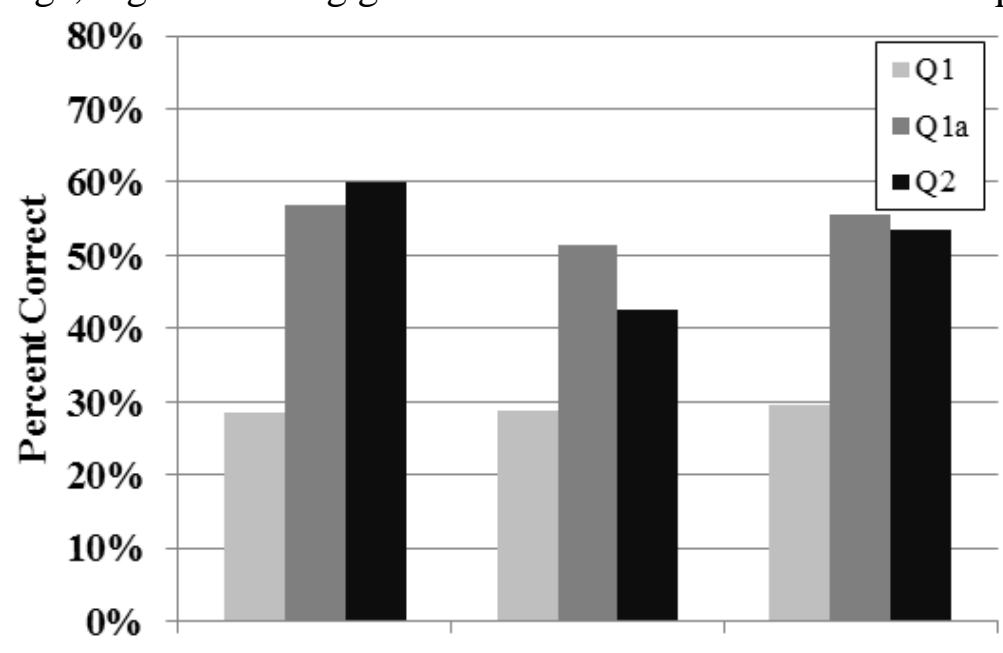

Above Median Below Median All Students

Figure 5. Correct response rates for the modified peer instruction sequences divided by course performance

Table 3. Learning gains for the modified peer instruction sequences divided by course performance

\begin{tabular}{|c|c|c|}
\cline { 2 - 3 } \multicolumn{1}{c|}{} & LG & NLG \\
\hline Above Median & $31 \%$ & $44 \%$ \\
\hline Below Median & $14 \%$ & $20 \%$ \\
\hline All Students & $24 \%$ & $34 \%$ \\
\hline
\end{tabular}

\section{Numeric Problems}

Student responses were recorded during the group problem sessions and classified as correct, incorrect, or "Not Enough Time" (NET), which was a permitted response if students ran out of class time to arrive at a solution. For each of the two instructional sequences (see Table 1) the percentage of students answering the numeric problem correctly was calculated using Equation 5 .

$$
\% \text { Correct }=\frac{\sum_{\mathrm{GPS}=1}^{n}(\# \text { of Students Correct })_{\mathrm{GPS}}}{\sum_{\mathrm{GPS}=1}^{\mathrm{n}}(\# \text { of Student Responses })_{\mathrm{GPS}}}
$$


The percentage of students responding NET was calculated in a similar fashion. The response patterns of students scoring above and below the median course grade were also calculated. The results are depicted in Table 4.

Table 4. Student responses to group problems based on problem solving sequence

\begin{tabular}{|c|c|c|c|c|}
\cline { 3 - 5 } \multicolumn{2}{c|}{} & $\begin{array}{c}\text { Above } \\
\text { Median }\end{array}$ & $\begin{array}{c}\text { Below } \\
\text { Median }\end{array}$ & $\begin{array}{c}\text { All } \\
\text { Students }\end{array}$ \\
\hline $\begin{array}{c}\text { Sequence 1 } \\
(\mathbf{n}=14)\end{array}$ & \% Correct & $71 \%$ & $56 \%$ & $64 \%$ \\
\cline { 2 - 5 } & NET & $10 \%$ & $13 \%$ & $11 \%$ \\
\hline $\begin{array}{c}\text { Sequence } 2 \\
(\mathbf{n}=6)\end{array}$ & \% Correct & $81 \%$ & $67 \%$ & $74 \%$ \\
\cline { 2 - 5 } & NET & $7 \%$ & $7 \%$ & $7 \%$ \\
\hline
\end{tabular}

NET - Percentage of students voting "not enough time"

Three trends are apparent. First, regardless of sequence, above median students were correct more often than their below median counterparts indicating a better grasp of numerical solution techniques. Second, regardless of grouping, students performed better when the group problem solving session immediately followed a similar instructor led problem (e.g. sequence 2 ). This result is not surprising since the numeric solution technique had just been explained by the instructor and was fresh in the student's minds. Lastly, the NET response rate increased when the instructor led problem solving and group problem solving sessions were held on different days. Instructor observations suggest that students spent class time during sequence 1 going back over their notes from the previous instructor led problem, reducing the available time to solve the current group problem with their peers and causing the increased NET response.

\section{Concept Inventory}

Two concept inventory exams were distributed during the course. The first exam (pre-course) was assigned during the first week of the course while the second exam (post-course) was assigned during the final week of the course. Only students who completed both concept inventory exams are included in the following data, the results of which are summarized in Table 5. The correlation coefficient between student overall course grades and the post-course inventory exam scores was found to be significant $(\mathrm{P}=0.48, \mathrm{n}=28, \mathrm{p}<0.01)$.

Table 5. Statics concept inventory (SCI) exam results

\begin{tabular}{|c|c|c|c|}
\cline { 2 - 4 } \multicolumn{1}{c|}{} & $\begin{array}{c}\text { Above } \\
\text { Median }\end{array}$ & $\begin{array}{c}\text { Below } \\
\text { Median }\end{array}$ & $\begin{array}{c}\text { All } \\
\text { Students }\end{array}$ \\
\hline Pre-Course SCI Average & $16 \%$ & $24 \%$ & $19 \%$ \\
\hline Post-Course SCI Average & $44 \%$ & $31 \%$ & $40 \%$ \\
\hline SCI Normalized Learning Gain & $33 \%$ & $9 \%$ & $25 \%$ \\
\hline Number of Students & 18 & 10 & 28 \\
\hline
\end{tabular}


The normalized learning gain for all students, calculated using Equation 6, was found to be on par with traditionally taught physics courses $(\mathrm{NLG}=23 \%)$ but below courses taught using interactive-engagement methods $(\mathrm{NLG}=48 \%)^{[19]}$.

$$
\text { Normalized Learning Gain }=\mathrm{NLG}=\frac{(\% \text { Post })-(\% \text { Pre })}{100 \%-(\% \text { Pre })}
$$

The results were also lower than the published findings of Dollár and Steif ${ }^{[9]}$ who obtained a normalized learning gain of 59\% in an interactive Statics course. This underperformance is believed to stem from the current course's numeric emphasis. Recall that only twenty-percent of in-class time was spent on conceptually focused activities and the course exams were primarily numeric. This numeric emphasis may have distracted from conceptual development: as the course progressed students (especially underperforming students) likely focused their study efforts on understanding numeric techniques (in order to maximize their grade) and less time on developing conceptual understanding. This theory is supported by the much smaller post-course inventory exam average obtained by below median students. Additional support comes from survey responses (see next section): students reported dissatisfaction with the interactive online textbook (conceptual emphasis) preferring to read the traditional textbook.

\section{Student Surveys}

Three surveys were distributed during the semester to gauge student opinion on course activities. In the first two surveys students were asked to score the various course components in terms of their helpfulness using a Likert-scale. In the third survey students were instead asked to rank the activities. The survey results, which are depicted in Figure 6, result in two observations. First, students generally indicated that numeric activities (group problem solving, instructor led problem solving, and homework \& recommended problems) were the most helpful. Second, students consistently preferred the traditional textbook over the interactive online textbook. 


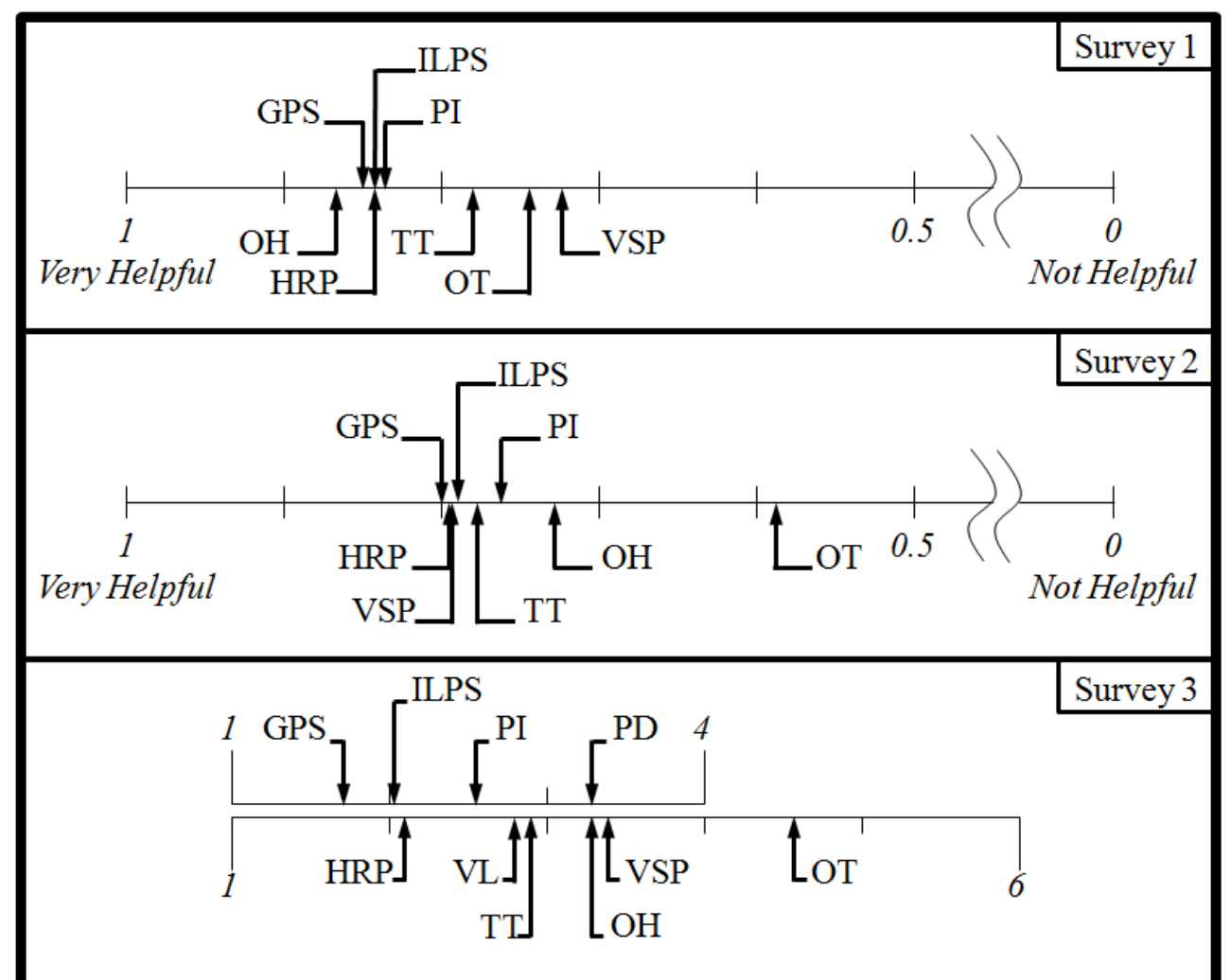

GPS - Group Problem Solving

ILPS - Instructor Led Problem Solving

PI - Peer Instruction

PD-Physical Demonstrations
$\mathrm{OH}$ - Office Hours

HRP-Homework \& Recommended Problems

TT - Traditional Textbook

OT-Online Textbook

VSP- Videos of Solved Numeric Problems

VL-Videos of Traditional Lectures

Figure 6. Perceived helpfulness: Likert scale (surveys 1 and 2) and ranking (survey 3)

In addition to activity rankings, the third survey asked students which activities they recommend to be used in future courses. These results are presented in Table 6. Students obtaining a below median course grade recommended numeric activities (group problem solving, instructor led problem solving, and homework \& recommended problems) with greater vigor than above median students. Above median students were more open to the continued use of conceptually focused activities (peer instruction and physical demonstrations) than their below median counterparts. These observations, along with the two observations stemming from Figure 6, support the theory outlined in the concept inventory results section: the courses numeric emphasis caused students (especially below median students) to focus their studies on numeric problem solving techniques. 
Table 6. Percentage of students recommending a stated activity be continued in future courses

\begin{tabular}{|c|c|c|c|}
\cline { 2 - 4 } \multicolumn{1}{c|}{} & $\begin{array}{c}\text { Above } \\
\text { Median }\end{array}$ & $\begin{array}{c}\text { Below } \\
\text { Median }\end{array}$ & $\begin{array}{c}\text { All } \\
\text { Students }\end{array}$ \\
\hline Group Problem Solving (GPS) & $80 \%$ & $100 \%$ & $89 \%$ \\
\hline Instructor Led Problem Solving (ILPS) & $93 \%$ & $100 \%$ & $96 \%$ \\
\hline Peer Instruction (PI) & $80 \%$ & $71 \%$ & $75 \%$ \\
\hline Physical Demonstrations (PD) & $80 \%$ & $57 \%$ & $68 \%$ \\
\hline Video Lectures (VL) & $77 \%$ & $93 \%$ & $85 \%$ \\
\hline Videos of Solved Problems (VSP) & $50 \%$ & $71 \%$ & $59 \%$ \\
\hline Interactive Online Textbook (OT) & $25 \%$ & $36 \%$ & $28 \%$ \\
\hline Traditional Textbook (TT) & $88 \%$ & $86 \%$ & $87 \%$ \\
\hline Office Hours (OH) & $100 \%$ & $100 \%$ & $100 \%$ \\
\hline Homework \& Recommended Problems (HRP) & $88 \%$ & $100 \%$ & $93 \%$ \\
\hline
\end{tabular}

The most overwhelming finding was student dissatisfaction with the interactive online textbook. Written comments also indicated student frustration with in-class reading quizzes. Most likely those students who did not like (or complete) the readings from the online textbook did not want to be quizzed on the material.

Three contradictions are noted when comparing Figure 6 and Table 6 . First, although students perceived group problem solving to be more beneficial to their learning (Figure 6), a slightly larger majority of students recommended instructor led problem solving be used in future courses (Table 6). Second, even though office hours were not consistently thought to be the most helpful activity (Figure 6) they were universally recommended for future inclusion (Table 6). Lastly, video lectures were more strongly recommended for future inclusion than videos of solved problems even though the video lectures primarily consisted of videos of solved problems. It is interesting to note that these three cases all indicate student preference towards "traditional" activities (instructor led problem solving, office hours, and videos of traditional lectures).

The third survey asked students if they would recommend future courses be taught in a nontraditional manner (e.g. using the hybrid environment described in this paper). Student responses (see Table 7) indicate a slight majority of all students prefer the non-traditional course structure with above median students showing greater support. The authors attribute this split recommendation to (1) student dissatisfaction with the online textbook and in-class reading quizzes and (2) the numeric emphasis used during the course. It is now believed that the hybrid environment was not properly structured to emphasize and reward conceptual understanding to the same degree other interactive-engagement courses do. 
Table 7. Percentage of students recommending the stated classes to be taught in a nontraditional manner

\begin{tabular}{|c|c|c|c|}
\cline { 2 - 4 } \multicolumn{1}{c|}{} & $\begin{array}{c}\text { Above } \\
\text { Median }\end{array}$ & $\begin{array}{c}\text { Below } \\
\text { Median }\end{array}$ & $\begin{array}{c}\text { All } \\
\text { Students }\end{array}$ \\
\hline Statics & $67 \%$ & $47 \%$ & $57 \%$ \\
\hline Dynamics & $61 \%$ & $47 \%$ & $54 \%$ \\
\hline
\end{tabular}

\section{Conclusions and Recommendations}

An interactive Statics course incorporating components of a traditional classroom, an inverted classroom, and those suggested by noted researchers in the field of Statics education were combined to form a hybrid learning environment. Findings relate to peer instruction, numeric problem solving, course learning gains, and student feedback as follows: (a) The use of isomorphic questions in a modified peer instruction sequence revealed student learning gains stemming from the peer discussions. These gains are in agreement with published research in other fields. (b) The sequence in which instructor led numeric problem solving and group numeric problem solving sessions were implemented resulted in a difference in the correct response rate of students. It was found that students perform slightly better on group numeric problems when instructor led problems occurred just before the group problem solving sessions. (c) The use of a Statics concept inventory exam showed the hybrid learning environment produced normalized learning gains comparable to traditional courses (25\% vs. $23 \%)$ but less than other interactive-engagement courses ( $25 \%$ vs. $48 \%, 59 \%)$. This underperformance is attributed to the numeric emphasis of the described course along with a grading scheme that favored numerical mastery over conceptual understanding. (d) Surveys showed that students strongly recommended the continued use of numeric focused activities in future courses and strongly discouraged the use of the interactive online textbook used during the semester. This, again, is likely due to the course's emphasis on numeric problem solving.

The following recommendations regarding component implementation are made:

- The learning gains from peer instruction warrant the continued use of peer instruction.

- Numeric problem solving sessions should be continued but at a reduced frequency. Although having both problem solving sessions on the same day results in improved student responses, the sequencing does not appear so critical that occasionally splitting the sessions (say to have one long numeric problem in a day rather than two short problems) is infeasible.

- The interactive online textbook should be a recommended rather than a required resource.

Although not scientifically tested here, the instructor believes the following changes would improve the student experience in the described course:

- Provide students a low-cost workbook containing isomorphic versions of the in-class concept questions, a discussion of the questions, and simple numeric problems that reinforce the targeted concept. Having the conceptual questions and numeric problems 
side-by-side may help students bridge the gap between the concept and the required mathematics.

- Replace the multiple choice reading quizzes. Crouch and Mazur ${ }^{[20]}$ found open ended questions more useful with the added benefit that student responses can be used to guide in-class discussions.

- Make homework suggested and not required. This change results in four benefits: (1) the importance of numeric problem solving is de-emphasized, (2) instructor time can be spent improving conceptual activities (e.g. peer instruction questions and physical demonstrations) instead of grading, (3) student time can be better distributed between studying numeric problem solving techniques and developing conceptual understanding, and (4) this change eliminates concerns of student cheating including the use of solution manuals.

- Replace the videos of solved problems, available through the online companion to the traditional textbook, with videos of the instructor solving the suggested homework problems.

The described Statics course is being updated with the above recommendations and will be implemented in future versions of the course. Future refinements are expected as the course structure evolves based on student feedback and future innovations in engineering education.

\section{References}

[1] Heller, P., and Hollabaugh, M. (1992). Teaching problem solving through cooperative grouping. Part 2: Designing problems and structuring groups. American Journal of Physics, 60(7), 637-644.

[2] Fagen, A. P., Crouch, C. H., and Mazur, E. (2002). Peer instruction: Results from a range of classrooms. The Physics Teacher, 40(4), 206-209.

[3] Demirel, Y. (2004, June). Effective teaching and active learning of engineering courses with workbook strategy. In Proceedings of the 2004 American Society for Engineering Education Annual Conference \& Exposition.

[4] Vander Schaaf, R., and Klosky, J. L. (2005). Classroom demonstrations in introductory mechanics. Journal of Professional Issues in Engineering Education and Practice, 131(2), 83-89.

[5] Dollár, A., and Steif, P. (2008a). An interactive, cognitively informed, web-based Statics course. International Journal of Engineering Education, 24(6), 1229.

[6] Steif, P. S., Lobue, J. M., Kara, L. B., \& Fay, A. L. (2010). Improving problem solving performance by inducing talk about salient problem features. Journal of Engineering Education, 99(2), 135-142.

[7] Mason, G. S., Shuman, T. R., \& Cook, K. E. (2013). Comparing the effectiveness of an inverted classroom to a traditional classroom in an upper-division engineering course. Education, IEEE Transactions on, 56(4), 430-435.

[8] Steif, P. S., \& Dollár, A. (2005). Reinventing the teaching of statics. International Journal of Engineering Education, 21(4), 723.

[9] Dollár, A., \& Steif, P. S. (2006). Learning modules for statics. International Journal of Engineering Education, 22(2), 381-392.

[10] Dollár, A., Steif, P. S., and Strader, R. (2007, October). Enhancing traditional classroom instruction with web-based Statics course. In Frontiers In Education Conference-Global Engineering: Knowledge Without Borders, Opportunities Without Passports, 2007. FIE'07. 37th Annual (pp. F1H-1). IEEE.

[11] Dollár, A., \& Steif, P. S. (2008b, October). Web-based Statics Course: Patterns in Use and the Relation to Learning Gains. In 2013 IEEE Frontiers in Education Conference (FIE) (pp. S2F-20). IEEE. 
[12] Smith, M. K., Wood, W. B., Adams, W. K., Wieman, C., Knight, J. K., Guild, N., and Su, T. T. (2009). Why peer discussion improves student performance on in-class concept questions. Science, 323(5910), 122-124.

[13] Porter, L., Bailey Lee, C., Simon, B., and Zingaro, D. (2011, August). Peer instruction: do students really learn from peer discussion in computing? In Proceedings of the seventh international workshop on Computing education research (pp. 45-52). ACM.

[14] Mazur, E. (1997). Peer Instruction: A User's Manual, Prentice Hall, Upper Saddle River, NJ.

[15]Fagen, A. P., Crouch, C. H., Yang, T., and Mazur, E. (2000, January). Factors That Make Peer Instruction Work: A 700-User Survey. In talk given at the 2000 AAPT Winter Meeting, Kissimmee, FL.

[16] Steif, P. S., \& Dollár, A. (2003, June). A new approach to teaching and learning statics. In Proceedings of the 2003 American Society for Engineering Education Annual Conference \& Exposition 2003, Nashville.

[17] James, M. C., and Willoughby, S. (2011). Listening to student conversations during clicker questions: what you have not heard might surprise you! American Journal of Physics, 79(1), 123-132.

[18] Steif, P. S., \& Dantzler, J. A. (2005). A statics concept inventory: Development and psychometric analysis. Journal of Engineering Education, 94(4), 363-371.

[19] Hake, R. R. (1998). Interactive-engagement versus traditional methods: A six-thousand-student survey of mechanics test data for introductory physics courses. American journal of Physics, 66(1), 64-74.

[20] Crouch, C. H., and Mazur, E. (2001). Peer instruction: Ten years of experience and results. American Journal of Physics, 69(9), 970-977. 